Book Review

\title{
Sociology in Iran
}

By Ali Akbar Mahdi and Abdolali Lahsaeizadeh. Bethesda,
MD: Jahan Book Co., 1992, 141 pp.

The book, with the help of empirical data, provides valuable information about the development of sociology as a discipline in Iran. It explains how the discipline was introduced in one of the colleges of Tehran in 1946 and gradually, over a span of twenty-five years, became a popular subject of teaching and research. The number of qualified students and staff is also steadily increasing. But more importantly, Iran now has a uniform B.A. degree program consisting of 144 credit hours in eight 17 -week semesters. Five categories of courses related to different areas and subareas are provided: general, base, main, elective, and specialized courses. In all of these courses, sociology and its various branches are mentioned.

The M.A. degree program has been developed with the intention of preparing a competent cadre of future teachers for the higher centers of learning. The program is similar to that found in European and American universities, with the exception of courses on the social thought of Muslim thinkers and the social ideas of Muslim philosophers, theologians, intellectuals, and historians. A doctoral program has also been introduced for training university faculty and researchers. The program requires thirty credit hours over a period of seven semesters. Out of these credit hours, twenty-two are required courses 
and the remaining are electives. One survey lists thirty-two research institutions, working under government agencies and various universities, that are actively engaged in studying various issues. Efforts have also been made to prepare sociological literature to cater to the needs of students and researchers. According to one estimate, up until 1989 (i.e., both before and after the revolution), a total of 521 books of sociology had been translated and 975 books had been written.

One significant fact that is discussed in the book is the indigenization of sociology. The authors describe two aspects of the development of Iranian sociology: prerevolutionary and postrevolutionary. The first period is marked by three major trends: conventional, radical, and synthesized which, in one way or the other, are manifestations of Western intellectual ethos and its interpretation in the Iranian situation. They explained social phenomena from a Western viewpoint. The second period, however, brought about drastic change in the sociopolitical scene and influenced the minds and souls of people in general and of the educated in particular. Sociologists, influenced by these developments, found new strength and revitalized the efforts to indigenize the discipline. They felt a strong need to reshape and restructure sociology's conceptual and theoretical bases according to Iran's sociocultural ethos, value system, normative perspective, and worldview.

The process of indigenization was initiated in the prerevolutionary period by social scientists such as Al-i Ahmad who found Western perspectives and parameters to be inadequate and irrelevant to acquiring an understanding and then explaining the social realities of Third World societies. It was strengthened and revitalized after the revolution by the patronage of a political elite committed to the Islamization of Iranian society. Indigenous social thinkers began to think anew and tried to develop models and paradigms according to the ideological framework of Islam. They found that any knowledge meaningfully associated with the normative system, particularly in the case of the human and the social worlds, should be in consonance with the basic tenets of revealed knowledge, which constitutes an alternative ideological system.

This intellectual effort led to the emergence of Islamic sociology. Shariati, the first to use this phrase in Iran, made rigorous effort to Islamize sociological knowledge. Social scientists in Iran found basic differences between Islamic and Western social thought. They thus demarcated the two views. Zarshanas and Surush are among the more prominent sociologists. Iranian sociologists have tried to define, explain, and elaborate Islamic sociology and concepts of sociological importance. Remarkably, three approaches to Islamic sociology have been developed. The first is the reconstructionist approach, which treats sociology as "the science dealing with the laws of social life of humans ...." The second is Feqahati's "New Sociology," which is explained as the knowledge of society and its variables when under the control of the vilayet-e faqih. The third stresses the study of classical and contemporary Is- 
lamic scholars. It highlights the issues with which they dealt, because later on, such issues became the subject matter of Western social thinking.

The themes discussed above clearly indicate that Iranian sociologists have struggled to develop indigenous sociological thought in order to understand social issues and analyze human actions in their own sociocultural setting. They, of course, deserve praise for not blindly following the footsteps of Western sociologists and interpreting social realities in terms of Western experience. The book, in this respect, is very significant, for it narrates the tedious journey that Iranian scholars have undertaken for intellectual transformation. It will be of great utility for social scientists and researchers of Third World countries who should learn from the Iranian experience and repeat it in their own region.

Jamil Farooqui Department of Sociology and Anthropology International Islamic University Selangor, Malaysia
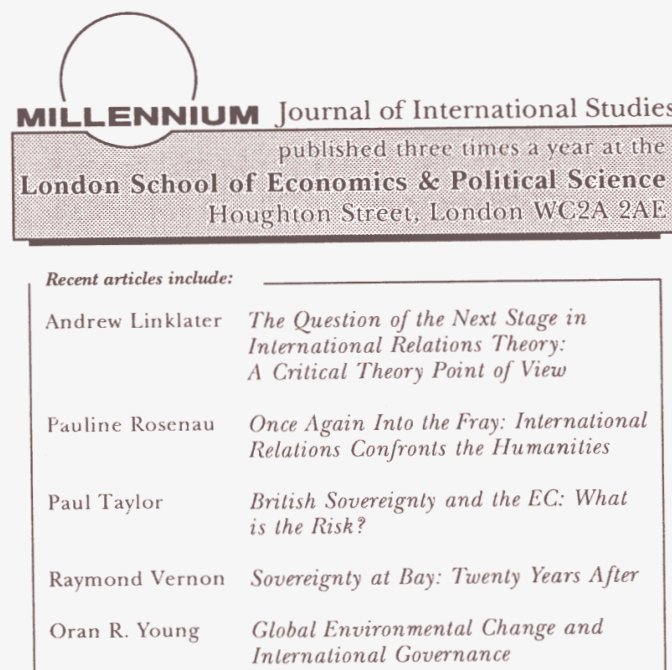

MILLENNIUM offers an extensive Book Reviews section in each issue and regular Discussion and Review sections.

Culture and International Relations 